\title{
Short-Term Effects of the Use of Non-Rigid Tools for Postural Control by Adults with Intellectual Disabilities
}

\author{
Eliane Mauerberg-deCastro, Renato Moraes \\ and Debra Frances Campbell
}

\begin{abstract}
We tested the short-term effects of a nonrigid tool, identified as an "anchor system" (e.g., ropes attached to varying weights resting on the floor), on the postural stabilization of blindfolded adults with and without intellectual disabilities (ID). Participants held a pair of anchors-one in each hand, under three weight conditions $(250 \mathrm{~g}, 500 \mathrm{~g}$ and $1,000 \mathrm{~g})$, while they performed a restricted balance task (standing for $30 \mathrm{~s}$ on a balance beam placed on top of a force platform). These conditions were called anchor practice trials. Before and after the practice trials, a condition without anchors was tested. Control practice groups, who practiced blocks of trials without anchors, included individuals with and without ID. The anchor system improved subjects' balance during the standing task, for both groups. For the control groups, the performance of successive trials in the condition without the anchor system showed no improvement in postural stability. The individuals with intellectual disability, as well as their peers without ID, used the haptic cues of nonrigid tools (i.e., the anchor system) to stabilize their posture, and the short-term stabilizing effects appeared to result from their previous use of the anchor system.
\end{abstract}

Keywords: haptic perception; postural control; non-rigid tools; anchor system; intellectual disability

Historically, the role of haptics in the action-perception system has been examined relative to individuals' acquisition of information during their performance of exploratory motor actions (Sanders \& Kappers, 2009; Solomon \& Turvey, 1988). Some researchers have specifically investigated the haptic system's functional role on postural control (Riley, Stoffregen, Grocki \& Turvey, 1999; Carello, Silva, Kinsella-Shaw \& Turvey, 2008; Holden, Ventura \& Lackner, 1994). The current study explores the contribution of haptic perception to the basic function of postural control through individuals' manual use of nonrigid tools, during their maintenance of the upright stance.

It has been demonstrated that when individuals touch a hard surface lightly with the index finger-even at very low force levels so that mechanical support is not

Mauerberg-deCastro and Campbell are with São Paulo State University at Rio Claro, Brazil, Moraes is with the University of São Paulo at Ribeirão Preto, Brazil. 
possible (i.e., $\sim 0.4 \mathrm{~N}$ ), haptic cues from the finger tend to help stabilize posture, and can reduce body sway amplitude of up to $50 \%$ (Jeka, 1997; Jeka \& Lackner, 1994; Lackner \& DiZio, 2005). The cues from such fingertip contact are so robust that the time required for this haptic stabilization of posture to occur can be as little as 300 ms (Rabin, DiZio \& Lackner, 2006; Rabin, DiZio, Ventura \& Lackner, 2008). Information provided by the haptic system is integrated with other sensoriallygathered information (i.e., vestibular and somatosensory information, for example), which in turn provides a frame of reference during the process of postural control.

Routine examples of light touch can be observed when individuals explore their surroundings with rigid tools (canes and ski poles, for example), or when they touch the handrails of a staircase. While such "tools" may provide mechanical support, the body's contact with these surfaces is itself a source of sensory information, which is used during the stabilization process. The stabilization of body sway can also be achieved through touch contact with nonrigid surfaces. For instance, children commonly pull and push on a parent's arm while trying to remain stable when walking on a balance beam. During the performance of such postural tasks there is a constant negotiation between postural states and the continuously changing, dynamic information that the nonrigid surface provides.

Indeed, humans are able to detect distal information that is mediated by objects or tools, whether rigid (Jeka, 1997) or nonrigid (Kinsella-Shaw \& Turvey, 1992). These haptic cues serve not only to orient posture, but are so remarkably efficient that they can also provide information as to the location of appended (occluded) objects, especially those related to distance. This manipulation of such "extensions" is what Kinsella-Shaw and Turvey (1992) refer to as the "exploitation of mechanical waves" (Kinsella-Shaw \& Turvey, 1992).

Mauerberg-deCastro $(2003 ; 2004)$ investigated the use of nonrigid tools in postural control in the laboratory, employing what she calls an "anchor system." To use this system, the individual is asked to hold the loose end of an "anchor," which consists of a rope attached to weights of varying degrees of heaviness, and which rest on the floor by the individual's sides. Mauerberg-deCastro (2004) demonstrated that this "non-rigid tool" acted as a type of "anchorage" system by providing stability to the organism. She identified a significant reduction in the amount of sway during the use of such an anchor system as young adults performed a one-foot standing task while blindfolded. In this study, the varying degrees of the anchors' heaviness were used to exploit the possible mechanical support that the anchors might provide. Our rationale was that the heavier weight $(1,000 \mathrm{~g}$ anchor condition) would give more support than the lighter weights. However, a similar postural sway outcome throughout all of the anchor weight conditions suggested that the subjects pulled the anchors with a similar force level, which was likely below $125 \mathrm{~g}$ (i.e., the lightest anchor load), regardless of actual anchor weight.

The anchor (or weight) and the anchor extension (e.g., rope) provide stability to an individual so that postural orientation (e.g., balance) can be maintained in relation to an adjacent surface (e.g., the floor). If the individual's body is displaced (e.g., loss of balance due to perturbation), his or her orientation will change as the tension on the anchor extension is modified (e.g., the rope stretches or tightens). The use of the anchor system requires some level of attention to the task because the instructions require the participant to maintain balance control while at the same time exploiting the anchor system as an aid during the balance task (MauerbergdeCastro, Lucena, Cuba, Boni, Campbell \& Moraes, 2010). 
Individuals with intellectual disabilities (ID) are known to have deficits in their postural control systems. Furthermore, they do not typically overcome balance problems during development, and frequently continue to experience them as they age (Mauerberg-deCastro \& Kinzler, 2000; Shumway-Cook \& Woollacott, 1985). Because ID individuals suffer from diminished attention, we would expect that the use of the anchor system would be a challenging task. In addition, several investigators have determined that attention can play an important role in balance control during fingertip touch performance tasks such as those used in the light touch paradigm studies of postural control (Jeka, 1997; Pettersson, Olsson \& Wahlund, 2007; Vuillerme, Isableu \& Nougier, 2006). A recent investigation by MauerbergdeCastro and collaborators (Mauerberg-deCastro et al., 2010) demonstrated that ID individuals benefited from use of the anchor system, even when the participants were challenged with a higher attention demand balance task (i.e., balancing on a $20 \mathrm{~cm}$-high balance beam) as compared with a lower attention demand task (i.e., balancing on a $10 \mathrm{~cm}$-high balance beam). Although the anchor system appeared to improve the ID individuals' postural control, it was not known whether this benefit would transfer to a nonanchor system condition.

The purpose of this study, then, was to assess the short-term effect of the "anchor system" on blindfolded adults with intellectual disabilities, who performed a restricted balance task (standing on a balance beam). It was expected that the anchor system would improve their balance, but, more importantly, that they would benefit from using the system for a short period of time. That is, it was expected that the removal of the anchor system after a few trials would result in an improvement in balance control as compared with the condition without the anchor system. Using two other independent groups, both with and without ID, a control task protocol was designed to assess whether performance of the balance task itself (i.e., several repetitions of the condition without the anchor system) would be enough to improve balance.

\section{Methods}

\section{Participants}

Twenty-one participants with intellectual disability (ID) and twenty participants without intellectual disability (ND) took part in this study (Tables 1 and 2). The ID participants were students at a local institution for special education and were classified as having either mild or moderate intellectual disability. Participants were randomly assigned to an experimental (practice with the anchor system), or control (practice without the anchor system) groups. Then four groups were created: ID without anchor, ID with anchor, ND without anchor, and ND with anchor.

The criteria for inclusion required that the participants, both with and without ID, had no history of balance problems or sickness at the time of participation. This information was gathered from the ND participants through individual interviews. For the participants with ID, this information was obtained from parents and the institution's reports. All participants or legal guardians signed a consent form designed specifically for this study, which was approved by our university's Ethics Committee.

Initially, thirty participants with ID were invited to participate in the study, but three of them, who were assigned to the anchor practice group, were unable to manipulate the anchor system. Six were unable to stand blindfolded on the balance beam and were dismissed from the experiment. 


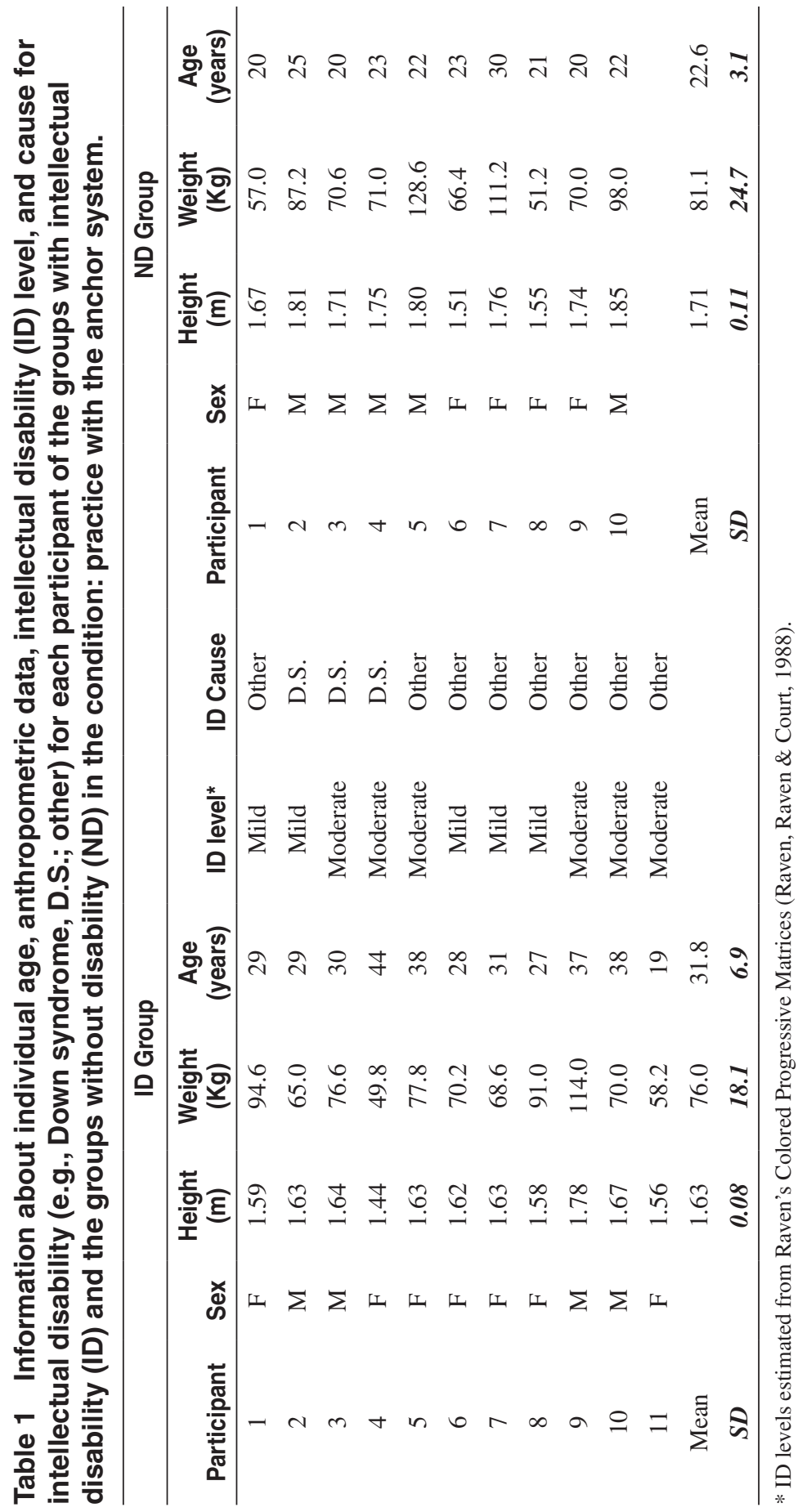




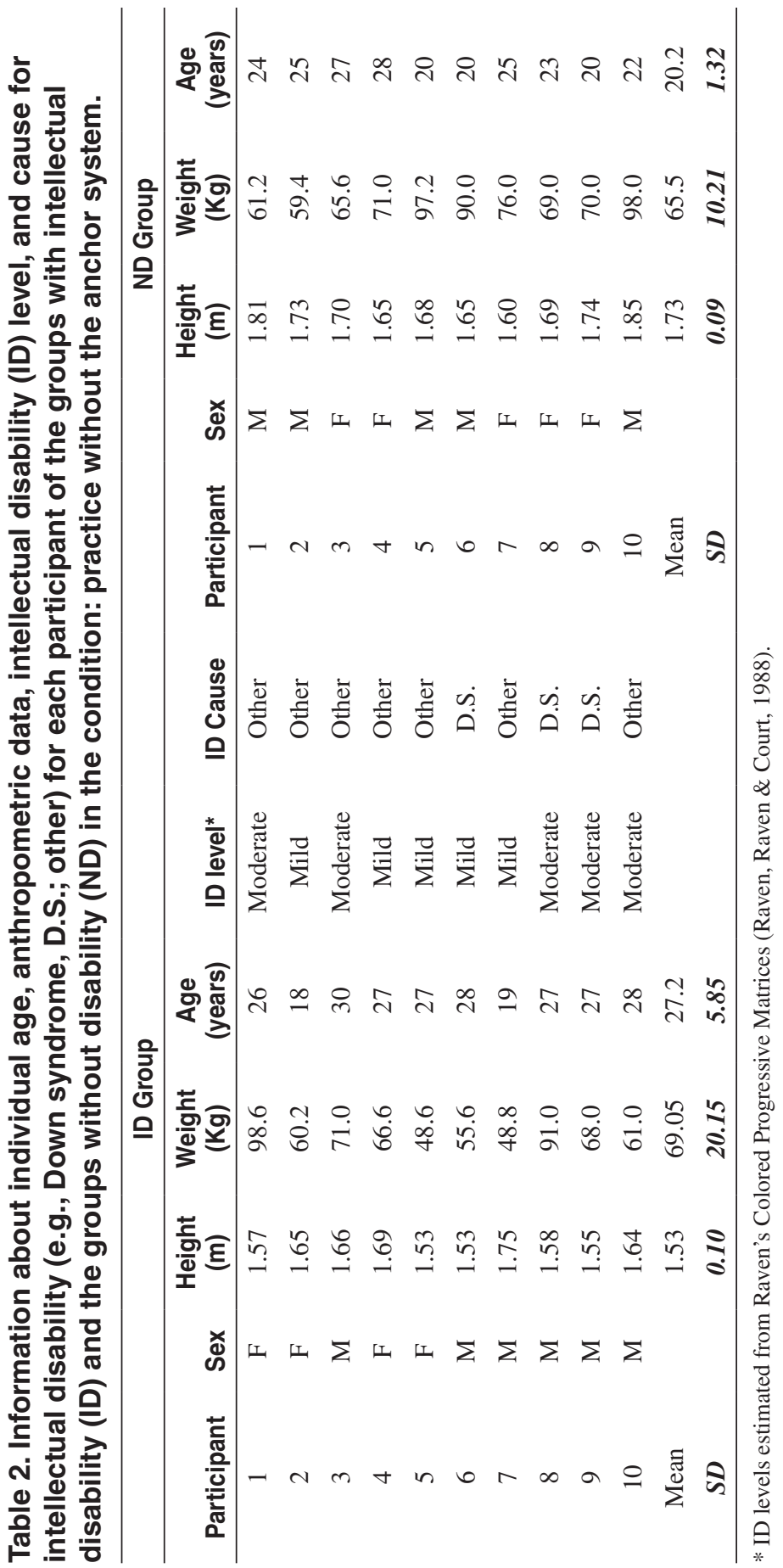




\section{Procedure}

Participants were asked to perform an upright standing task while wearing a blindfold goggle to obstruct vision. Participants stood barefoot on $10 \mathrm{~cm}$ high balance beams, which varied in three different widths (i.e., $\sim 10 \mathrm{~cm}, \sim 20 \mathrm{~cm}, \sim 30 \mathrm{~cm}$ ). The width was customized, based on the participant's foot size, so that it provided support only to the middle part of the sole. Toes and heels had no contact with the beams. Each balance beam was centrally positioned on top of a force platform (AMTI, AccuGait, Watertown, MA, USA). The force platform was used to gather the kinetic variables of individuals in each group (i.e., individuals with intellectual disability and without intellectual disability). They were randomly assigned to either a control (without anchor practice) or to an experimental group (with anchor practice).

In the anchor practice group, participants in both the ID and ND groups practiced with the anchor system in three blocks of trials (see details below). The anchor system consisted of ropes attached to pairs of anchor mass-bags filled with metal shot-in three degrees of heaviness $(250 \mathrm{~g}, 500 \mathrm{~g}, 1,000 \mathrm{~g})$. Participants held the loose ends of an anchor pair, one in each hand, and were instructed to allow the other, weighted ends of the anchors to rest on the floor, by his or her sides (Figure 1). The selected weight loads were similar to those of an earlier study by Mauerberg-deCastro (2004) in an attempt to corroborate whether a similar outcome would recur with the current groups.

All participants performed a pretest (condition without the anchors) block, followed by three blocks of practice (i.e., with the anchors), and they were again tested in a posttest block. The condition without the anchors was tested immediately before (i.e., pretest) and after practice blocks (posttest). For the anchor practice groups (ID and ND), participants performed the three blocks of practice holding onto the anchors in the three different mass conditions ( $250 \mathrm{~g}, 500 \mathrm{~g}$ and 1,000 $\mathrm{g}$ ). The order of the anchor conditions were randomized for each participant. For each anchor mass, as well as for the conditions without anchors, participants performed three repetitions. The same number of trials (blocks and repetitions) was performed by the control groups (i.e., without anchor practice). The control groups (ID and ND) performed the five practice blocks without the anchors. To keep consistency when comparing results to the anchor practice group, we also called the first block of trials "pre-test" and the last block, "post-test." The three blocks in between we called "practice trials." The total number of trials for all of the blocks was 15. Participants in all four groups rested for $30 \mathrm{~s}$ between each block. All participants practiced at least one entire $30 \mathrm{~s}$ trial with the anchors (the experimental groups) and without the anchors (all groups) before the session started, so they had an opportunity to become familiar with the balance tasks. This practice was administered to ensure that the participants would be able to carry out the blindfolded postural task for 30 $\mathrm{s}$ without leaving the balance beam.

During the gathering of data on the force platform, one experimenter was always positioned in front of the participant to ensure safety if he or she were to fall off of the beam. Four participants (three ID and one ND) stepped off of the beam on one occasion, and immediately repeated their trial. These falls occurred in the first $10 \mathrm{~s}$ of the trials. During the anchor conditions, the experimenter gently verbally reminded the participants to maintain the anchor ropes tightly stretched. This strategy was employed whenever the experimenter noticed that the rope was becoming loose. 


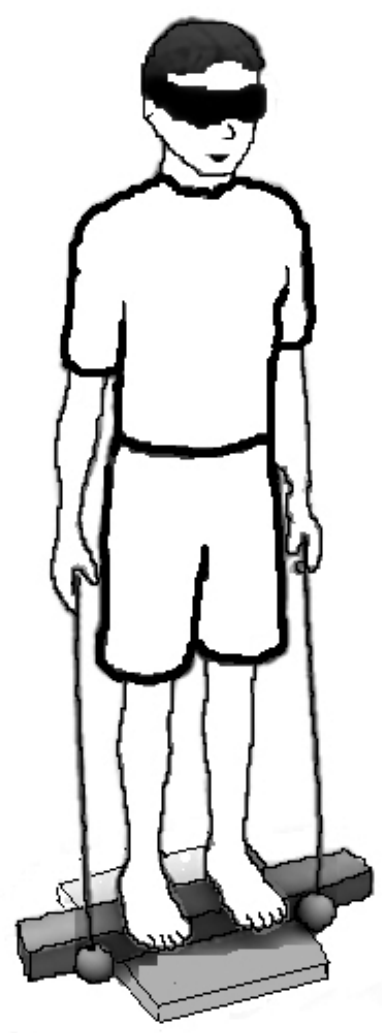

Figure 1 - Participant holding the anchor system while he attempts, blindfolded, to stand on a balance beam.

\section{Data Analyses}

Force plate data were sampled at $120 \mathrm{~Hz}$. Center-of-pressure (COP) displacement was calculated online by the Balance Clinic software (AMTI, Watertown, MA, USA) and registered in the same frequency. COP data were filtered through a fourth-order, low-pass digital Butterworth filter, with a cut-off frequency of $10 \mathrm{~Hz}$. Path length was computed as the dependent variable. Path length was calculated as the sum of the displacement scalars over the $30 \mathrm{~s}$ duration of each trial. A numeric increase in this variable is assumed to represent less stability, with a decrease representing more stability.

A two-way ANOVA (2 groups [ID and ND] $\times 3$ anchor weights [250 g, $500 \mathrm{~g}$, and $1,000 \mathrm{~g}]$ ) was performed to identify whether there was a main effect for anchor weight during blocks of practice. Analyses revealed that different anchor weights had no significant effect on the dependent variable. Therefore, the three anchor weights were treated as blocks of practice, independent of weight. In this way, a 2 $\times 2 \times 5$ (groups [ID and ND] $\times$ anchors [with and without] $\times$ blocks [pretest, block 1 , block 2, block 3, and posttest]) ANOVA with repeated measures in the last factor 
was carried out for path length. We used the mean value of the three repetitions of each block for statistical purposes.

When ANOVA identified main effect, we carried out the Bonferroni post hoc analysis to identify where the differences resided. The Bonferroni post hoc analysis uses $t$ tests for pairwise comparisons, and automatically adjusts the $p$-level for the number of comparisons to avoid Type I error. $P$-value was set at 0.05 for all statistical analyses. When ANOVA identified interaction effect, multiple $t$ tests, with Bonferroni adjustment, were carried out to identify where the difference resided.

\section{Results}

The three-way ANOVA (groups $\times$ anchors $\times$ blocks) showed main effects for groups $\left(\mathrm{F}_{1,37}=6.862, p=.013\right)$ and for blocks $\left(\mathrm{F}_{4,148}=26.099, p \leq .0001\right)$, and an interaction effect between blocks and anchors $\left(\mathrm{F}_{4,148}=10.967, p \leq .0001\right)$. Path length was longer for individuals with ID $(1.85 \pm 0.13 \mathrm{~m})$ than for the ND individuals $(1.35$ $\pm 0.14 \mathrm{~m})$. For the block effect, post hoc analysis showed that path length was longer for the pretest $(1.85 \pm 0.10 \mathrm{~m})$ than for all three blocks of practice (block 1: 1.55 $\pm 0.09 \mathrm{~m} \mid$ block 2: $1.53 \pm 0.09 \mathrm{~m} \mid$ block 3: $1.46 \pm 0.09 \mathrm{~m})(p \leq .0001)$. In addition, there were differences between pretest and posttest $(1.59 \pm 0.11 \mathrm{~m})(p=.001)$ and between B3 and posttest ( $p=.011)$.

For the interaction effect, multiple $t$ tests, with Bonferroni adjustment, were carried out $(0.05 / 25$ comparisons $=0.002)$. As shown in Figure 2, there was a sig-

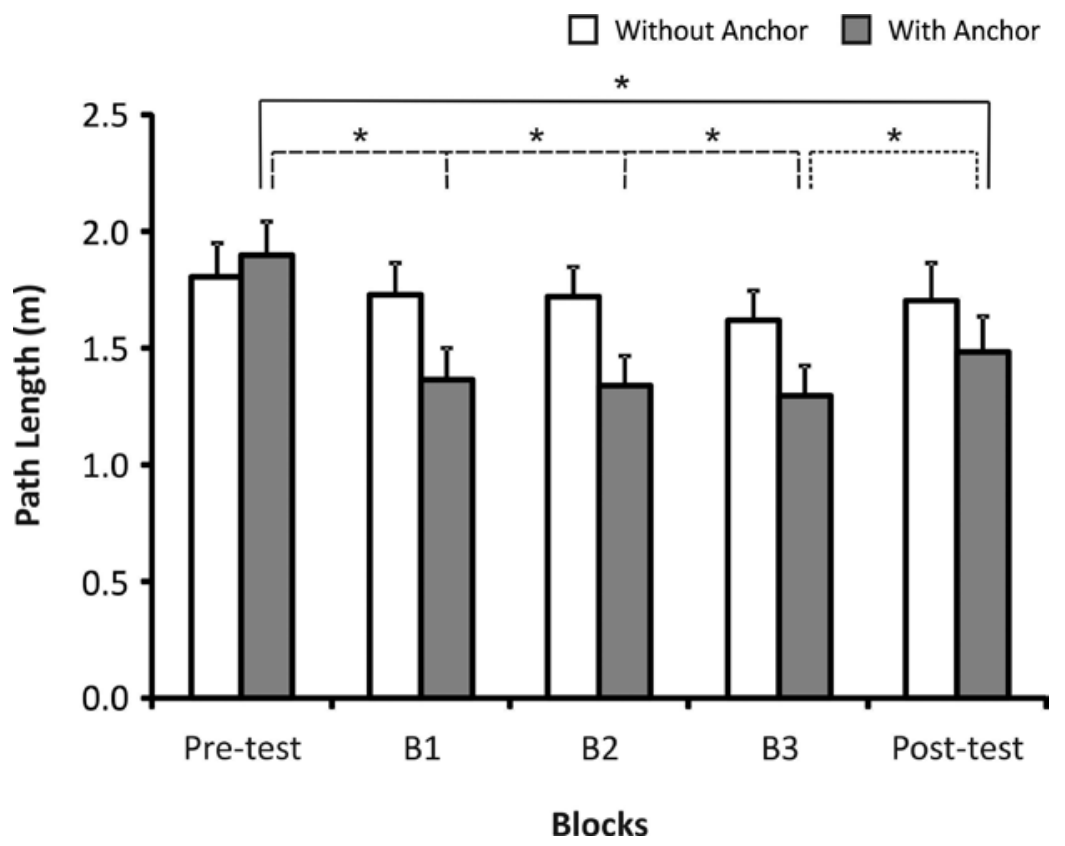

Figure 2 - Mean and standard error for path length for pre- and posttest, and blocks of practice for groups with and without anchor practice $(* p \leq .001)$. 
nificant difference between pre- and posttest only for the individuals who practiced with the anchor system $\left(t_{20}=5.665, p=.000015\right)$. The comparison between preand posttest for individuals who did not practice with the anchor system did not reach statistical significance $\left(\mathrm{t}_{19}=1.071, p=.298\right)$. In addition, only the individuals who practiced with the anchors reduced path length during blocks of practice as compared with those in the pretest (pretest vs. $\mathrm{B} 1: \mathrm{t}_{20}=7.688, p \leq .0001 \mid$ pretest vs. $\mathrm{B} 2: \mathrm{t}_{20}=8.302, p \leq .0001 \mid$ pretest vs. $\left.\mathrm{B} 3: \mathrm{t}_{20}=7.839, p \leq .0001\right)$. Although path length reduced from pre- to posttest, there was an increase in COP excursion from $\mathrm{B} 3$ to posttest $\left(\mathrm{t}_{20}=-4.342, p \leq .0001\right.$. The mean and standard deviation values are presented in Table 3.

These results confirm the hypothesis of the current study: that is, practice with the anchor system can fine-tune postural control, and the removal of the anchor system in the final block of trials resulted in a diminished excursion for the COP. These results also suggest that use of the anchor system improved postural control for both groups, with and without intellectual disability, for a short period of time.

Table 3 Mean and standard deviation of the path length $(\mathrm{m})$ for pre- and posttests and for the blocks of practice. (Groups with intellectual disability, ID; and groups without disability, ND)

\begin{tabular}{|c|c|c|c|c|c|c|c|}
\hline \multirow[b]{2}{*}{ Group } & \multirow[b]{2}{*}{ Anchor } & & \multirow[b]{2}{*}{ Pretest } & \multicolumn{3}{|c|}{ Practice: Without Anchor } & \multirow[b]{2}{*}{ Posttest } \\
\hline & & & & Block 1 & Block 2 & Block 3 & \\
\hline \multirow[t]{2}{*}{ ND } & Without & Mean & 1.56 & 1.48 & 1.36 & 1.28 & 1.33 \\
\hline & & $S D$ & 0.53 & 0.54 & 0.40 & 0.32 & 0.35 \\
\hline \multirow[t]{4}{*}{ ID } & Without & Mean & 2.05 & 1.99 & 2.08 & 1.96 & 2.09 \\
\hline & & $S D$ & 0.75 & 0.80 & 0.84 & 0.88 & 1.08 \\
\hline & & & & \multicolumn{3}{|c|}{ Practice: With Anchor } & \\
\hline & & & Pretest & $250 \mathrm{~g}$ & $500 \mathrm{~g}$ & $1,000 \mathrm{~g}$ & Posttest \\
\hline \multirow[t]{2}{*}{ ND } & With & Mean & 1.69 & 1.18 & 1.18 & 1.13 & 1.26 \\
\hline & & $S D$ & 0.38 & 0.36 & 0.31 & 0.36 & 0.42 \\
\hline \multirow[t]{2}{*}{ ID } & With & Mean & 2.10 & 1.55 & 1.49 & 1.46 & 1.70 \\
\hline & & $S D$ & 0.87 & 0.64 & 0.64 & 0.59 & 0.74 \\
\hline
\end{tabular}

\section{Discussion}

The anchor metaphor provides a model to describe how a biological system can build a dynamic mechanism (a subsystem) from a nonliving thing (i.e., an "anchor") to detect information to help it maintain or change its actual status as a system (Mauerberg-deCastro, 2004). When a biological system thus detects information that has been mediated by a tool such as a cane or rope, this relationship between environment and organism suggests that the nonbiological extension-acting as a subsystem of the organism-in effect becomes a part of it. In the case of our study, the individuals who used the anchor system seemed to use the extensions (i.e., the anchors) adaptively, to eliminate potential balance disruptions. 
Effectiveness of the anchor system was found in our previous studies (Mauerberg-deCastro, 2003; 2004; Mauerberg-deCastro et al., 2010; Moraes \& Mauerberg-deCastro, 2009). In the current study, we again confirmed that haptic information not only can be gathered efficiently by individuals known to exhibit balance problems (i.e., intellectual disability), but that this information appears to rapidly modify their intrinsic dynamics. In this study, the reduction in the amount of sway across all anchor conditions lead us to believe that nonrigid tools used to acquire haptic information might play an important role in the stabilization of posture. Both groups benefited from practice during the anchor blocks, reducing sway in the posttest condition; and, as compared with the pretest condition, both groups improved balance equally. However, a comparison of pre- and posttests revealed that the effects from the use of the anchors were greater for the nondisabled group. Intellectual disability seems not to have been a constraint in the performance of the task, and, when comparing the ID group's performance outcome in the anchor conditions in contrast with the pretest, their balance improvement was similar to their nondisabled peers (i.e., nearly 30\%). This similar outcome for both groups suggests that, while ID is characterized by a delayed, complex, and heterogeneous developmental condition, the ID participants in our study optimally used their haptic system to help stabilize their posture. It seems that their postural adaptation as a result of using the anchor system was not restricted by any developmental constraints that typically accompany intellectual disability (i.e., lack of attention).

In many ways, the anchor system appears to be similar to Holden and Lackner's light touch model (Holden, Ventura \& Lackner, 1994; Jeka \& Lackner, 1994). One similarity between the light touch model and the anchor system is that, in both, individuals use haptic information continuously, based on their perception of balance loss. In the light touch protocol, although the fingers' contact with the surface is continuous, the experimentally prescribed amount of finger pressure on the contact surface (i.e., typically $\sim 1 \mathrm{~N}$ ) reduces options for finger activity because the participants are operating at near terminal threshold force levels. With the anchor system, due to the relatively heavy mass of the anchors, the force threshold level for stabilization via touch is unknown. A limitation of the current study is that we did not monitor the amount of pull force in each hand during participants' manipulation of the anchors.

Another important difference between the anchor system and the light finger touch models is that, in the former, the directional forces move away from the ground. Yet, the meaning and utility of the force direction remain to be investigated. In practical terms, the anchor paradigm can be easily built and, more importantly, can be successfully used in dynamical tasks like walking (Calve \& Mauerberg-deCastro, 2005). The individual's manipulation of the anchor system, in conjunction with the performance of the balance task, appears to help with the fine-tuning of the details of limb orientation relative to the whole body and its perpendicularity to the surface.

The anchor system is a mechanism that reflects an inverted coupled pendulum. The anchor endpoints (i.e., the varied loads) are external objects, or extensions, that affect the individual's reference with regard to the surrounding spatial layout. But because the entire anchor system is "connected" to the individual, or organism, as a subsystem, the anchor system itself changes as a consequence of the manipulation. The outcome of the individual's controlling of the rope (i.e., the varying possibilities for its orientation) also feeds back into the action-perception system. 
The challenge here, then, is to identify a coherent control strategy, if there is one. An example of such a control strategy was demonstrated in an earlier MauerbergdeCastro study (2004), which employed a one-foot balance task performed by adults. The author found that for some participants who manipulated the anchor system, the trajectories of the right and left hands relative to the trunk displayed in- and of out-of-phase relationships for the duration of the task. For other participants, many of their segments' trajectories did not follow any obvious pattern for much of the duration of the task. Nevertheless, even though the anchor ropes acted to restrict the arms' movements, this coupled, multiarticulated system helped a majority of the participants to successfully complete the task requirements.

Another aspect of the current study was the testing of different mass loads. In our previous studies (Mauerberg-deCastro, 2004; Mauerberg-deCastro et al., 2010), an absence of differences between the anchor masses suggested that individuals possibly pull on the anchors at a relative low pull force. The participants with and without disability indicated at the end of the practice sessions their preference for the heavier anchors, which indicates that they recognize mechanical benefits in the heaviest mass. Yet, the results indicated that stabilization with the heavier mass was no greater than it was with the lighter mass. The individuals without disability reported that they felt more stable using the heaviest mass, but the data representing postural sway revealed no difference. Our current results corroborate these previous findings. However, our suspicions that participants use a fixed amount of pull have yet to be tested.

In summary, it is especially convincing that the anchor system can be useful as a means of postural control training, since transference effects at the end of the series appear to have improved the condition without anchors. Another study that employed the anchor system with nondisabled participants walking along on a balance beam showed that a significant transference in performance was achieved in the final, nonanchor conditions through the manipulation of the anchor conditions in previous trials (Mauerberg-deCastro, Calve, Viveiros, Polanczyk \& Cozzani, 2003). Individuals in a control group, who performed the postural task repeatedly, but without the anchors, did not benefit from such practice.

These data also suggest that a minimal amount of practice with the anchor system appears to cause short-term adaptation by the postural control system. Therefore, just as we found a robust effect of the anchor system in our earlier studies (Calve \& Mauerberg-deCastro, 2005; Mauerberg-deCastro, 2003; 2004; Mauerberg-deCastro et al., 2010; Moraes \& Mauerberg-deCastro, 2009), we have once again corroborated the same tendency for individuals who are known to have balance problems.

Our results provide evidence that a brief period of practice with the anchor system during a challenging balance task was enough to improve postural control in individuals both with and without intellectual disability. These results suggest that the anchor system might be a viable therapeutic tool for people who suffer from balance problems.

\section{Acknowledgments}

This study was supported by the Brazilian research agency, CNPq, and the UNESP-CNPqPibic program. We wish to thank the staff and directors of APAE (Association of Parents and Friends of People with Intellectual Disability), Rio Claro, Brazil, and the participants with 
intellectual disabilities who volunteered for this study. In addition, we would like to thank the members of the Laboratory of Action and Perception (Gabriella A. Figueiredo, Gabriella F. Braga, Camila S. Lucena, and Ana Carolina Panhan), who helped during data collection. Finally, we greatly appreciate the MC anonymous reviewers' insightful reviews of this paper.

\section{References}

Calve, T., \& Mauerberg-deCastro, E. (2005). Contribuição da percepção háptica no controle postural de crianças (Haptic Contribution to postural control in children). Motriz, 11, 199-204.

Carello, C., Silva, P.L., Kinsella-Shaw, J.M., \& Turvey, M.T. (2008). Muscle-based perception: theory, research and implications for rehabilitation. Revista Brasileira de Fisioterapia, 12, 339-350 (Brazilian Journal of Physical Therapy).

Holden, M., Ventura, J., \& Lackner, J.R. (1994). Stabilization of posture by precision contact of the index finger. Journal of Vestibular Research, 4, 285-301.

Jeka, J.R. (1997). Light Touch Contact as a Balance Aid. Physical Therapy, 77, 476-487.

Jeka, J.J., \& Lackner, J.R. (1994). Fingertip contact influences human postural control. Experimental Brain Research, 100, 495-502.

Kinsella-Shaw, J.M., \& Turvey, M.T. (1992). Haptic perception of object distance in a singlestrand vibratory web. Perception \& Psychophysics, 52, 625-638.

Lackner, J.R., \& DiZio, P. (2005). Vestibular, Proprioceptive, and Haptic Contributions to Spatial Orientation. Annual Review of Psychology, 56, 115-147.

Mauerberg-deCastro, E. (2003). Expansão da sensibilidade háptica através de um sistema "âncora" durante o andar sob restrição visual e de equilíbrio (Expanding haptic sensitivity using na anchor system while walking under visual and balance restrictions). Relatório de pesquisa CAPES (Technical Research Report). Brasil.

Mauerberg-deCastro, E. (2004). Developing an anchor system to enhance postural control. Motor Control, 8, 339-358.

Mauerberg-deCastro, E., \& Angulo-Kinzler, R. (2000). Locomotor patterns of individuals with Down syndrome: Effects of environmental and task constraints. In D. Elliot, R. Chua, \& D. Weeks (Eds.), Perceptual-motor behavior in Down syndrome (pp. 71-98). Urbana, Champaign: Human Kinetics.

Mauerberg-deCastro, E., Calve, T., Viveiros, F.F., Polanczyk, S., \& Cozzani, M.V. (2003). Um Tutorial Sobre Percepção Háptica no Controle Postural: Ilustrando um Sistema "âncora" e suas Aplicações na Reabilitação e na Atividade Física Adaptada (A tutorial about haptic perception in postural control: Illustrating an "anchor" system and its applications in rehabilitation and adapted physical activity). Revista da Sociedade Brasileira de Atividade Motora Adaptada, 8, 7-20 (Brazilian Journal of Adapted Motor Activity).

Mauerberg-deCastro, E., Lucena, C.S., Cuba, B.W., Boni, R.C., Campbell, D.F., \& Moraes, R. (2010). Haptic stabilization of posture in adults with intellectual disabilities using a non-rigid tool. Adapted Physical Activity Quarterly, 27, 208-225.

Moraes, R., \& Mauerberg-deCastro, E. (2009). O uso de ferramenta não-rígida reduz a oscilação corporal em indivíduos idosos (The use of non-rigid tools reduce postural sway in older individuals). Motriz, 15, 263-272.

Pettersson, A.F., Olsson, E., \& Wahlund, L. (2007). Effect of Divided Attention on Gait in Subjects With and Without Cognitive Impairment. Journal of Geriatric Psychiatry and Neurology, 20, 58-62.

Rabin, E., DiZio, P., \& Lackner, J.R. (2006). Time course of haptic stabilization of posture. Experimental Brain Research, 170, 122-126.

Rabin, E; DiZio, P. Ventura, J. \& Lackner, J.R. (2008). Influences of arm proprioception and degrees of freedom on postural control with light touch feedback. Journal of Neurophysiology, 99, 595-604. 
Raven, J.C., Raven, J., \& Court, J.H. (1988). Matrizes Progressivas Coloridas de Raven. Manual (Manual for Raven's Progressive Matrices). São Paulo: Casa do Psicólogo.

Riley, M.A., Stoffregen, T.A., Grocki, M.J., \& Turvey, M.T. (1999). Postural stabilization for the control of touching. Human Movement Science, 18, 795-817.

Sanders, A.F.J., \& Kappers, A.M.L. (2009). Factors affecting the haptic filled-space illusion for dynamic touch. Experimental Brain Research, 192, 717-722.

Solomon, H.Y., \& Turvey, M.T. (1988). Haptically perceiving the distances reachable with hand-held objects. Journal of Experimental Psychology. Human Perception and Performance, 14, 404-427.

Shumway-Cook, A., \& Woollacott, M. (1985). The growth of stability: postural control from a developmental perspective. Journal of Motor Behavior, 17, 131-147.

Vuillerme, N., Isableu, B., \& Nougier, V. (2006). Attentional demands associated with the use of a light fingertip touch for postural control during quiet standing. Experimental Brain Research, 169, 232-236. 
Copyright of Motor Control is the property of Human Kinetics Publishers, Inc. and its content may not be copied or emailed to multiple sites or posted to a listserv without the copyright holder's express written permission. However, users may print, download, or email articles for individual use. 